\title{
Impact of intracellular toxic advanced glycation end- products (TAGE) on murine myoblast cell death: $A$ non-clinical study
}

Takanobu Takata ( $\nabla$ takajjjj@kanazawa-med.ac.jp )

Kanazawa Ika Daigaku

Akiko Sakasai-Sakai

Kanazawa Ika Daigaku

Masayoshi Takeuchi

Kanazawa Ika Daigaku

\section{Research}

Keywords: Sarcopenia, Myoblasts, Glyceraldehyde, Toxic advanced glycation end-products, Non-alcoholic steatohepatitis, C2C12 cells, STAM mouse

Posted Date: May 13th, 2020

DOI: https://doi.org/10.21203/rs.2.23269/v2

License: (a) (1) This work is licensed under a Creative Commons Attribution 4.0 International License. Read Full License 


\section{Abstract}

Background: Sarcopenia is a progressive condition that is characterized by decreases in skeletal muscle mass and function. Although previous studies reported that sarcopenia is associated with non-alcoholic steatohepatitis (NASH), the underlying mechanisms remain unclear. We herein focused on glyceraldehyde, an intermediate of glucose/fructose metabolism. We previously designated glyceraldehyde-derived advanced glycation end-products (AGEs) as toxic AGEs (TAGE) because of their cytotoxicity and involvement in lifestyle-related diseases, such as NASH. We hypothesized that TAGE is associated with sarcopenia.

Methods: C2C12 cells, which are murine myoblasts, were treated with $0,0.5,1,1.5$, and $2 \mathrm{mM}$ glyceraldehyde for $24 \mathrm{~h}$. Cell viability and intracellular TAGE were then assessed using 5-[2,4,Bis(sodioxysulfonyl)phenyl]-3-(2-methoxy-4-nitrophenyl)-2-(4-nitrophenyl)-2H-tetrazole-3-ium (WST-8) and slot blot assays. Cells were pretreated with $8 \mathrm{mM}$ aminoguanidine, an inhibitor of AGE production, for $2 \mathrm{~h}$ followed by $0,1.5$, and $2 \mathrm{mM}$ glyceraldehyde for $24 \mathrm{~h}$. Cell viability and intracellular TAGE were then assessed. Serum TAGE levels in STAM mice, in which there were four stages (no steatosis, simple steatosis, steatohepatitis, and fibrosis), were measured using an enzyme-linked immunosorbent assay.

Results were expressed as TAGE units (U) per milliliter of serum, with $1 \mathrm{U}$ corresponding to $1.0 \mu \mathrm{g}$ of glyceraldehyde-derived AGE-bovine serum albumin (BSA) (TAGE-BSA). The viability of cells treated with 20, 50, and $100 \mu \mathrm{g} / \mathrm{mL}$ non-glycated BSA and TAGE-BSA for $24 \mathrm{~h}$ was assessed using the WST-8 assay. Results: In C2C12 cells treated with 1.5 and $2 \mathrm{mM}$ glyceraldehyde, cell viability decreased to $47.7 \%$ ( $p$ $=0.0021)$ and $5.0 \%(p=0.0001)$ and intracellular TAGE levels increased to 6.0 and $15.9 \mu \mathrm{g} / \mathrm{mg}$ protein, respectively. Changes in cell viability and TAGE production were completely inhibited by $8 \mathrm{mM}$ aminoguanidine. Serum TAGE levels at the steatohepatitis and fibrosis stages were $10.51 \pm 1.16$ and $10.44 \pm 0.95 \mathrm{U} / \mathrm{mL}$, respectively, and were higher than that at the no steatosis stage $(7.27 \pm 0.18 \mathrm{U} / \mathrm{mL})$. Cell death was not induced by 20 or $50 \mu \mathrm{g} / \mathrm{mL}$ TAGE-BSA. The viabilities of C2C12 cells treated with 100 $\mu \mathrm{g} / \mathrm{mL}$ non-glycated BSA and TAGE-BSA were 105.0\% $(p=0.2890)$ and $85.3 \%(p=0.0217)$, respectively.

Conclusion: Intracellular TAGE strongly induce myoblast cell death and may cause sarcopenia. Therefore, TAGE may play a crucial role in sarcopenia associated with NASH .

\section{Background}

Skeletal muscle requires exercise, the synthesis of glycogen, and interactions with other organs, such as the liver and adipose tissue [1]. Sarcopenia is a progressive condition that is characterized by decreases in skeletal muscle mass and function, resulting in the deterioration of activities of daily living and quality of life as well as increases in the risk of falls and mortality [2]. Skeletal muscle consists of myotubes that differentiate from myoblasts; therefore, one of the mechanisms contributing to the loss of skeletal muscle is the death of or dysfunctions in myoblasts [2-6]. Accumulating evidence has shown that patients with non-alcoholic steatohepatitis (NASH) have an increased risk of sarcopenia $[2,7,8]$. However, 
the relationships between myoblast cell damage and NASH remain unclear. Mastrocola et al. previously reported that the levels of the $N^{\varepsilon}$-carboxymethyllysine (CML) and $N^{\varepsilon}$-carboxyethyllysine (CEL)-modified proteins, which are advanced glycation end-products (AGEs), were elevated in the skeletal muscle of C57BI6j mice and OB/OB mice, which is an obese model mouse, and identified abnormalities in skeletal muscle (including the loss of skeletal muscle mass, myosteatosis, and oxidative stress) $[9,10]$. Although CML and CEL-modified proteins have been suggested to play a role in sarcopenia, the relationships between $\mathrm{CML}, \mathrm{CEL}$, and $\mathrm{NASH}$ remain unclear.

We herein focused on glyceraldehyde, an intermediate of glucose/fructose metabolism, because we previously designated glyceraldehyde-derived AGEs as toxic AGEs (TAGE) based on their cytotoxicity and involvement in lifestyle-related diseases, such as NASH, type 2 diabetes mellitus (T2DM), cardiovascular diseases, dementia, and cancer [11-15]. In a clinical study, we revealed that intracellular TAGE were generated in the livers of NASH patients, and serum TAGE levels were also elevated in these patients [1115]. Therefore, we hypothesized that TAGE, but not CML or CEL-modified proteins, may cause sarcopenia associated with NASH. TAGE appear to be generated in myoblasts and induce cytotoxicity based on previous findings showing their production in neuroblastoma cells, hepatic cells, pancreatic cells, and cardiac cells as well as their induction of cell death and dysfunction [16-22]. In the present study, we examined extracellular TAGE, such as TAGE in blood, which may be secreted or released from organs that generate intracellular TAGE, because they may induce cytotoxicity, including inflammation and oxidative stress $[11-13,15,23]$.

\section{Methods}

\section{Reagents, cell lines, and serum of STAM mice}

Dulbecco's modified Eagle's medium (DMEM) and penicillin-streptomycin solution were obtained from Sigma-Aldrich (MO, USA). Fetal bovine serum (FBS) was purchased from Bovogen-Biologicals (VIC, Australia). Glyceraldehyde was purchased from Nacalai Tesque Inc. (Kyoto, Japan). The 5-[2,4,Bis(sodioxysulfonyl)phenyl]-3-(2-methoxy-4-nitrophenyl)-2-(4-nitrophenyl)-2H-tetrazole-3-ium (WST-8) assay kit and 3-[(3-cholamido-propyl)-dimethyl-ammonio]-1-propane sulfonate) (CHAPS) were obtained from Dojindo Laboratories (Kumamoto, Japan). The ethylene diamine-N,N,N',N'-tetraacetic acid (EDTA)free protease inhibitor cocktail was obtained from Roche Applied Science (Penzberg, Germany). C2C12 cells were obtained from KAC Co., Ltd. (Kyoto, Japan). The serum of STAM mice was purchased from SMC Laboratories, Inc. (Tokyo, Japan). The protein assay kit for the Bradford method was obtained from Takara Bio, Inc. (Otsu, Japan). A horseradish peroxidase (HRP)-linked molecular marker was obtained from Bionexus (CA, USA). A HRP-linked goat anti-rabbit IgG antibody was purchased from DAKO (Glostrup, Denmark). All other reagents and kits not indicated were purchased from Fujifilm Wako Pure Chemical Co. (Osaka, Japan). GA-derived AGE-bovine serum albumin (BSA) (TAGE-BSA), non-glycated BSA, and an anti-TAGE antibody were prepared as described previously [24]. 
Cell culture and cell seeds. C2C12 cells were incubated in DMEM supplemented with $10 \% \mathrm{FBS}, 100 \mathrm{U} / \mathrm{mL}$ penicillin, and $100 \mathrm{mg} / \mathrm{mL}$ streptomycin under standard cell culture conditions (humidified atmosphere, $\left.5 \% \mathrm{CO}_{2}, 37^{\circ} \mathrm{C}\right)$. Cells were seeded $\left(1.9 \times 10^{4} \mathrm{cells} / \mathrm{cm}^{2}\right)$ on 96 -well microplates and culture dishes (BectonDickinson, NJ, USA).

Glyceraldehyde and aminoguanidine treatments of C2C12 cells. Glyceraldehyde was dissolved in phosphate-buffered saline (PBS) without $\mathrm{Ca}^{++}$and $\mathrm{Mg}^{++}((\mathrm{PBS})(-))$, and then filtered before being added to $\mathrm{C} 2 \mathrm{C} 12$ cells. The volume of PBS (-) (including glyceraldehyde) was $2.0 \mu \mathrm{L} / 100 \mu \mathrm{L}$ of the total medium volume. All experiments were performed $24 \mathrm{~h}$ after treatments with $0,0.5,1,1.5$, and $2 \mathrm{mM}$ glyceraldehyde. The cell culture method before the treatment with aminoguanidine (the volume of PBS (-) (including aminoguanidine) was $2.0 \mu \mathrm{L} / 100 \mu \mathrm{L}$ of the total medium volume), an inhibitor of AGE production, was the same as that described above. Cells were pretreated with 0 or $8 \mathrm{mM}$ aminoguanidine for $2 \mathrm{~h}$ followed by $0,1.5$, and $2 \mathrm{mM}$ glyceraldehyde for $24 \mathrm{~h}$ (the volume of PBS(-) (including glyceraldehyde) was $2.0 \mu \mathrm{L} / 102 \mu \mathrm{L}$ of the total medium volume).

Cell viability of $\mathrm{C} 2 \mathrm{C} 12$ cells treated with glyceraldehyde and aminoguanidine. Cell viability was assessed using the WST-8 assay. Medium containing glyceraldehyde/aminoguanidine was removed and cells were washed with PBS (-). Ten microliters of WST-8 reagent was added to 96-well microplates in which C2C12 cells were cultured in medium $(100 \mu \mathrm{L})$, and this was followed by an incubation at $37^{\circ} \mathrm{C}$ for $2 \mathrm{~h}$ in a $\mathrm{CO}_{2}$ incubator. Absorbance was measured at 450 and $655 \mathrm{~nm}$ using a microplate reader (Bio-Rad, CA, USA). Medium in the wells without cells was treated with glyceraldehyde/aminoguanidine, a medium change, and WST-8 reagent to measure background absorbance. Background absorbance was subtracted from experimental values.

\section{Assessment of intracellular TAGE in C2C12 cells treated with glyceraldehyde and aminoguanidine using a} slot blot analysis. This analysis was performed as described previously with some modifications [20-22]. Cells were washed with (PBS)(-) and then lysed in buffer [a solution of $2 \mathrm{M}$ thiourea, $7 \mathrm{M}$ urea, $4 \% \mathrm{CHAPS}$, and $30 \mathrm{mM}$ Tris, and a solution of EDTA-free protease inhibitor cocktail (9:1)]. Cell extracts were then incubated on ice for $20 \mathrm{~min}$, centrifuged at $10,000 \times \mathrm{g}$ at $4^{\circ} \mathrm{C}$ for $15 \mathrm{~min}$, and the supernatant was collected as the cell extract. Protein concentrations were measured using the protein assay kit for the Bradford method with BSA as a standard. Regarding the detection of TAGE, equal amounts of cell extracts, the HRP-linked molecular marker, and TAGE-BSA were loaded onto polyvinylidene difluoride (PVDF) membranes ( $0.45 \mu \mathrm{m}$; Millipore, MA, USA) fixed in the slot blot apparatus (Bio-Rad). PVDF membranes were cut to prepare two membranes and then blocked at room temperature (r.t.) for $1 \mathrm{~h}$ using $5 \%$ skimmed milk in PBS(-) containing $0.05 \%$ Tween 20 (skimmed milk-PBS-T). After this step, we used $0.5 \%$ of skimmed milk-PBS-T for washing or as the solvent of antibodies. After washing twice, membranes 
were incubated with (1) the anti-TAGE antibody $(1: 1,000)$ or $(2)$ neutralized anti-TAGE antibody (a mixture of the anti-TAGE antibody $(1: 1,000)$ and $250 \mu \mathrm{g} / \mathrm{mL}$ of TAGE-BSA) at $4^{\circ} \mathrm{C}$ overnight. Membranes were then washed four times. Proteins on the membrane were incubated with the HRP-linked goat anti-rabbit IgG antibody $(1: 2,000)$ at r.t. for $1 \mathrm{~h}$. After washing three times with PBS-T, membranes were moved into PBS(-). Immunoreactive proteins were detected with the ImmunoStar LD kit and band densities on the membranes were measured using the Fusion FX fluorescence imager (M\&S Instruments Inc., Osaka, Japan). The densities of HRP-linked molecular marker bands were used to correct for differences in densities between membranes. The amount of TAGE in cell extracts was calculated based on a calibration curve for TAGE-BSA.

Analysis of serum TAGE levels in STAM mice. Briefly, each well of the 96-well microplate was coated with $1.0 \mu \mathrm{g} / \mathrm{mL}$ TAGE-BSA and incubated overnight in a cold room. Wells were washed three times with $0.3 \mathrm{~mL}$ of PBS containing $0.05 \%$ Tween 20 (PBS-T). Wells were then blocked by an incubation for $1 \mathrm{~h}$ with 0.2 $\mathrm{mL}$ of a solution of PBS containing $1 \%$ BSA. After washing with PBS-T, test samples $(50 \mu \mathrm{L})$ were added to each well as a competitor for $50 \mu \mathrm{L}$ of the anti-TAGE antibody $(1: 1,000)$, followed by an incubation at r.t. for $2 \mathrm{~h}$ with gentle shaking on a horizontal rotary shaker. Wells were then washed with PBS-T and developed with alkaline phosphatase-linked anti-rabbit IgG utilizing p-nitrophenyl phosphate as the colorimetric substrate. Results were expressed as TAGE units $(U)$ per milliliter of serum, with $1 \mathrm{U}$ corresponding to $1.0 \mu \mathrm{g}$ of a TAGE-BSA standard as described previously [24]. Sensitivity and intra- and interassay coefficients of variation were $0.01 \mathrm{U} / \mathrm{mL}$ and 6.2 and $8.8 \%$, respectively [25].

Non-glycated BSA and TAGE-BSA treatment of C2C12 cells and assessment of cell viability. C2C12 cells were treated with 0,2050 , and $100 \mu \mathrm{g} / \mathrm{mL}$ of non-glycated BSA and TAGE-BSA, and then incubated for 24 h. Cell viability was measured using the WST-8 assay. The ratio of cell viability was calculated based on the viability of cells treated with TAGE-BSA versus those treated with non-glycated BSA.

Statistical analysis. Stat Flex (ver. 6) software (Artech Co., Ltd., Osaka, Japan) was used for statistical analyses. Data were expressed as means \pm standard deviation (S.D.). When statistical analyses were performed on data, significant differences in the means of each group were assessed by a one-way analysis of variance (ANOVA). We then used the Bonferroni or Tukey's test for an analysis of variance. Pvalues $<0.05$ were considered to be significant.

\section{Results}

Viability of $\mathrm{C} 2 \mathrm{C} 12$ cells treated with glyceraldehyde. The viability of $\mathrm{C} 2 \mathrm{C} 12$ cells treated with 0.5 and 1 $\mathrm{mM}$ glyceraldehyde did not decrease, whereas dose-dependent decreases to 47.7 and $5.0 \%$ were observed 
in those treated with 1.5 and $2 \mathrm{mM}$ glyceraldehyde, respectively (Fig. 1a).

Quantity of intracellular TAGE in C2C12 cells treated with glyceraldehyde. Intracellular TAGE were not generated in $\mathrm{C} 2 \mathrm{C} 12$ cells treated with $0,0.5$, and $1 \mathrm{mM}$ glyceraldehyde (Fig. $1 \mathrm{~b}$ ). Intracellular TAGE dosedependently increased to 6.0 and $15.9 \mu \mathrm{g} / \mathrm{mg}$ protein in C2C12 cells treated with 1.5 and $2 \mathrm{mM}$ glyceraldehyde, respectively (Fig. 1b).

Effects of the aminoguanidine pretreatment on the viability of $\mathrm{C} 2 \mathrm{C} 12$ cells treated with glyceraldehyde. The viability of $\mathrm{C} 2 \mathrm{C} 12$ cells treated with 1.5 and $2 \mathrm{mM}$ glyceraldehyde without aminoguanidine dosedependently decreased to 35.0 and $3.0 \%$, respectively (Fig. 1C). In C2C12 cells pretreated with $8 \mathrm{mM}$ aminoguanidine, cell viabilities were $71.7,71.3$, and $74.3 \%$ in those subsequently treated with $0,1.5$, and 2 $\mathrm{mM}$ glyceraldehyde, respectively. No significant differences were observed between each treatment (Fig. 1c). The aminoguanidine pretreatment completely inhibited decreases in the viability of $\mathrm{C} 2 \mathrm{C} 12$ cells treated with 1.5 and $2 \mathrm{mM}$ glyceraldehyde.

\section{Effects of the aminoguanidine pretreatment on the quantity of intracellular TAGE in C2C12 cells treated with glyceraldehyde. Glyceraldehyde concentrations of 1.5 and $2 \mathrm{mM}$ without aminoguanidine dose- dependently increased intracellular TAGE to 7.9 and $13.4 \mu \mathrm{g} / \mathrm{mg}$ protein, respectively (Fig. 1d). Intracellular TAGE levels in C2C12 cells pretreated with $0 \mathrm{mM}$ aminoguanidine followed by $0 \mathrm{mM}$ glyceraldehyde and in those pretreated with $8 \mathrm{mM}$ aminoguanidine followed by $0,1.5$, and $2 \mathrm{mM}$ glyceraldehyde were not significantly different. The aminoguanidine pretreatment completely inhibited the generation of intracellular TAGE in C2C12 cells treated with 1.5 and $2 \mathrm{mM}$ glyceraldehyde.}

Serum TAGE levels in STAM mice. Serum TAGE levels in the pre-simple steatosis and simple steatosis stage groups were $7.27 \pm 0.18$ and $8.69 \pm 1.01 \mathrm{U} / \mathrm{mL}$, respectively (Fig. 2a). Serum TAGE levels in the steatohepatitis and fibrosis stage groups increased to $10.51 \pm 1.16$ and $10.44 \pm 0.95 \mathrm{U} / \mathrm{mL}$, which were higher than that in the pre-simple steatosis stage group.

Viability of C2C12 cells treated with non-glycated BSA and TAGE-BSA. No significant differences were observed in the viability of C2C12 cells treated with $0,20,50$, and $100 \mu \mathrm{g} / \mathrm{mL}$ of non-glycated BSA and TAGE-BSA (Figure S2). The viabilities of C2C12 cells treated with $100 \mu \mathrm{g} / \mathrm{mL}$ non-glycated BSA and TAGE-BSA were 105.0 and $85.3 \%$, respectively, and the ratio of cell viability was $81.2 \%$ (Fig. $2 \mathrm{~b}$ ). 


\section{Discussion}

Glyceraldehyde, which is a precursor of TAGE, is generated by the liver via three pathways $[11,15,23]$. $(1)$ Glucose is metabolized to glyceraldehyde via glycolysis. (2) Fructose is metabolized to glyceraldehyde via the pathway involving fructokinase and aldolase B (fructolysis). (3) Glucose is metabolized to fructose via the sorbitol pathway, which regulates aldose reductase and sorbitol dehydrogenase, and this fructose is metabolized to glyceraldehyde via fructolysis. Since skeletal muscle uses glycolysis and contains fructokinase, aldolase B, aldose reductase, and sorbitol dehydrogenase [26-28], we considered the three pathways of glyceraldehyde metabolism to occur in skeletal muscle, similar to the liver. $\mathrm{CML}$ and CEL are produced by some pathways from glucose $[11,15,23]$, and CEL is produced by the degradation of the products of fructoselysine in glycated proteins [29].

CML- and CEL-modified proteins have been suggested to cause sarcopenia in C57BI6j mice fed a high-fat high-sugar diet and a high-fructose diet and also in OB/OB mice fed a standard diet based on the loss of muscle mass, myosteatosis, and oxidative stress in the gastrocnemius of these animals $[9,10]$. AGEs have also been suggested to cause sarcopenia. However, we recently reported that the formation of TAGE was enhanced during NASH, and serum and hepatic TAGE levels, but not CML, were significantly higher in patients with NASH than in healthy human controls or patients with simple steatosis $[11,14]$. Moreover, the relationship between $\mathrm{CEL}$ and $\mathrm{NASH}$ remains unclear.

Therefore, we hypothesized that TAGE, but not CML or CEL-modified proteins, may cause sarcopenia associated with $\mathrm{NASH}$.

We predicted that intracellular TAGE are generated in myoblasts because they were previously shown to be produced in neuroblastoma cells, hepatic cells, pancreatic cells, and cardiac cells and induce cell death [16-22].

We treated $\mathrm{C} 2 \mathrm{C} 12$ cells with glyceraldehyde to rapidly generate intracellular TAGE. In the present study, $\mathrm{C} 2 \mathrm{C} 12$ cells were treated with glyceraldehyde at a physiological concentration to generate TAGE within 24 h. Taniguchi et al. previously demonstrated that islets of the pancreas exposed to $20 \mathrm{mM}$ glucose accumulated $0.025 \mathrm{pmol} /$ islet glyceraldehyde, whereas exposure to $10 \mathrm{mM}$ glucose caused the accumulation of $0.12 \mathrm{pmol} /$ islet glyceraldehyde [30]. Based on these findings, Takahashi et al. used 2 $\mathrm{mM}$ glyceraldehyde in their experiments, which is a similar concentration to $20 \mathrm{mM}$ glucose [31]. On the other hand, plasma levels of glucose in NASH and T2DM model mice increased by more than $25 \mathrm{mM}$ [3234]. The viability of $\mathrm{C} 2 \mathrm{C} 12$ cells treated with 1.5 and $2 \mathrm{mM}$ glyceraldehyde for $24 \mathrm{~h}$ dose-dependently decreased (Fig. 1a). In contrast, intracellular TAGE were generated in a dose-dependent manner. (Fig. 1b). To demonstrate that the generation of TAGE decreased cell viability, C2C12 cells were pretreated with 8 $\mathrm{mM}$ aminoguanidine, an inhibitor of the generation of AGEs, for $2 \mathrm{~h}$ followed by 1.5 and $2 \mathrm{mM}$ glyceraldehyde for $24 \mathrm{~h}$. Aminoguanidine inhibited decreases in cell viability as well as the generation of TAGE (Fig. 1c, d). To the best of our knowledge, this is the first study to show that intracellular TAGE were generated from glyceraldehyde at a physiological concentration in myoblasts and strongly induced cell death. The death of myoblasts will lead to the loss of skeletal muscle. Living myoblasts that generate 
intracellular TAGE may also ultimately lead to the loss of skeletal muscle. In our previous study, when rat primary cardiomyocytes were treated with $4 \mathrm{mM}$ glyceraldehyde for $6 \mathrm{~h}$, cell viability decreased to $39.2 \%$ and intracellular TAGE were generated at $12.0 \mu \mathrm{g} / \mathrm{mg}$ protein [22]. Furthermore, living cardiomyocytes completely stopped beating. The viability of $\mathrm{C} 2 \mathrm{C} 12$ cells treated with $1.5 \mathrm{mM}$ glyceraldehyde was $47.7 \%$ and living cells generated intracellular TAGE levels of $6.0 \mu \mathrm{g} / \mathrm{mg}$ protein (Fig. 1a, b). The generation of skeletal muscle may be inhibited in myotubes with dysfunctional differentiation [2-6]. Collectively, these findings and the present results suggest that the cell death or dysfunction of myoblasts that gain excess glucose or fructose and generate high levels of intracellular TAGE may inhibit the differentiation of myoblasts.

In STAM mice, which are a NASH model, serum TAGE levels were higher in the steatohepatitis and fibrosis stages than in the no steatosis stage (Fig. 2a). Since TAGE in blood induces responses, such as inflammation and oxidative stress, in some organs [11-13,15,23], we investigated the cytotoxicity of TAGE-BSA, a model of extracellular TAGE, in myoblasts. We applied 20, 50, and $100 \mu \mathrm{g} / \mathrm{mL}$ TAGE-BSA, which are approximately 2,5, and 10-fold, respectively, that of serum TAGE levels in STAM mice that develop steatohepatitis and fibrosis (Fig. 2 and Fig. S2). To examine the effects of TAGE in C2C12 cells, we assessed the viability of $\mathrm{C} 2 \mathrm{C} 12$ cells treated with non-glycated BSA and TAGE-BSA. Only $100 \mu \mathrm{g} / \mathrm{mL}$ TAGE-BSA slightly decreased cell viability (Fig 2d). Therefore, extracellular TAGE do not appear to induce cell death under physiological conditions.

\section{Conclusion}

The present study demonstrated that intracellular TAGE were generated in $\mathrm{C} 2 \mathrm{C} 12$ cells and more strongly induced cell death than extracellular TAGE. These results suggest that intracellular TAGE strongly induce myoblast cell death and cause sarcopenia. Therefore, TAGE may play a crucial role in sarcopenia associated with NASH.

\section{Abbreviations}

NASH: non-alcoholic steatohepatitis; AGEs: advanced glycation end-products; TAGE: toxic advanced glycation end-products

\section{Declarations}

Ethics approval and consent to particle

Not applicable.

Consent for publication 
Not applicable.

Availability of data and materials

The datasets used and/or analyzed during the present study are available from the corresponding author upon reasonable request.

Competing interests

The authors declare that they have no competing interests.

Funding

The present study was funded by JSPS KAKENHI (Grant Numbers JP16H01811 \& JP18K11139) and Assist KAKEN from Kanazawa Medical University (K2019-24).

Author contributions

TT and MT designed the research, TT and AS-S performed the research, MT contributed reagents that were indispensable for this investigation, TT and AS-S analyzed data, and TT and MT wrote the manuscript.

Acknowledgments

Not applicable.

Author information

Department of Advanced Medicine, Medical Research Institute, Kanazawa Medical University, Uchinadamachi, Ishikawa, Japan

\section{References}

1. Ronden M, Shulman GI. The integrative biology of type 2 diabetes. Nature. 2019;576(7785):51-60. 
2. Adachi N, Kanazawa I, Tanaka K, Takeno A, Notsu M, Tanaka S, et al. Insulin-like growth factor-I protects against the detrimental effects of advanced glycation end products and high glucose in myoblastic C2C12 cell. Calcif Tissue Int. 2019;105(1):89-96.

3. Sato H, Funaki A, Kimura Y, Sumitomo M, Yoshida H, Fukata H, et al. Ethanol extract of Cyclolepis genistoides Don (palo azul) induces formation of myotubes, which involves differentiation of $\mathrm{C} 2 \mathrm{C} 12$ myoblast cells. Nutr Res. 2016;36(7):731-741.

4. Burks TN, Cohn RD. Role of TGF- $\beta$ signaling in inherited and acquired myopathies. Skelet Muscle. 2011;1(1):19.

5. Byun SK, An TH, Son MJ, Lee DS, Kang HS, Lee EW, et al. HDAC11 inhibits myoblast differentiation through repression of MyoD-dependent transcription. Mol Cells. 2017;40(9):667-676.

6. Tanaka K, Kanazawa I, Yamaguchi T, Yano S, Kaji H, Sugimoto T. Active vitamin D possesses beneficial effects on the interaction between muscle and bone. Biochem Biophys Res Commun. 2014;450(1):482-487.

7. Bhanji RA, Narayanan P, Moynagh MR, Takahashi N, Angirekula M, Kennedy CC, et al. Differing impact of sarcopenia and frailty in nonalcoholic steatohepatitis and alcoholic liver disease. Liver Transpl. 2019;25(1):14-24.

8. Petta S, Ciminnisi S, Di Marco V, Cabibi D, Cammà C, Licata A, et al. Sarcopenia is associated with severe liver fibrosis in patients with non-alcoholic fatty liver disease. Aliment Pharmacol Ther. 2017;45(4):510-518.

9. Mastrocola R, Collino M, Nigro D, Chiazza F, D'Antona G, Aragno M et al. Accumulation of advanced glycation end-products and activation of SCAP/SREBP lipogenetic pathway occur in diet-induced obese mouse skeletal muscle. PLoS One 2015;10(3):e0119587.

10. Mastrocola R, Nigro D, Chiazza F, Medana C, Dal Bello F, Boccuzzi G et al. Fructose-derived advanced glycation end-products drive lipogenesis and skeletal muscle reprogramming via SREBP-1C dysregulation in mice. Free Radic. Biol. Med. 2016;91:224-235.

11. Takeuchi M. Serum levels of Toxic AGEs (TAGE) may be a promising novel biomarker for the onset/progression of lifestyle-related diseases. Diagnostics. 2016;6:23.

12. Takeuchi M, Takino J, Sakasai-Sakai A, Takata T, Tsutsumi M. Toxic AGE (TAGE) theory for the pathophysiology of the onset/progression of NAFLD and ALD. Nutrients. 2017;9:634.

13. Sakasai-Sakai A, Takata T, Takino J, Takeuchi M. The relevance of Toxic AGEs (TAGE) cytotoxicity to NASH pathogenesis: A mini-review. Nutrients. 2019;11:462.

14. Hyogo H, Yamagishi S, Iwamoto K, Arihiro K, Takeuchi M, Sato T, et al. Elevated levels of serum advanced glycation end products in patients with non-alcoholic steatohepatitis. J Gastroenterol Hepatol. 2007;22(7):1112-1119.

15. Takino J, Nagamine K, Hori T, Sakasa-Sakai A, Takeuchi M. Contribution of the toxic advanced glycation end-products-receptor axis in nonalcoholic steatohepatitis-related hepatocellular carcinoma. World J Hepatol. 2015;7(23):2459-2469. 
16. Koriyama Y, Furukawa A, Muramatsu M, Takino J, Takeuchi M. Glyceraldehyde caused Alzheimer's disease-like alterations in diagnostic marker levels in SH-SY5Y human neuroblastoma cells. Sci Rep. 2015;5:13313.

17. Takino J, Kobayashi Y, Takeuchi M. The formation of intracellular glyceraldehyde-derived advanced glycation end-products and cytotoxicity. J Gastroenterol. 2010;45(6):646-655.

18. Takino J, Nagamine K, Takeuchi M, Hori T. In vitro identification of nonalcoholic fatty liver diseaserelated protein hnRNPM. World J Gastroenterol. 2015;21(6):1784-1793.

19. Sakasai-Sakai A, Takata T, Takino J, Takeuchi M. Impact of intracellular glycation end-products on human hepatocyte cell death. Sci Rep. 2017;7(1):14282.

20. Takata T, Sakasai-Sakai A, Takino J, Takeuchi M. Evidence for toxic advanced glycation endproducts generated in the normal rat liver. Nutrients. 2019;11:1612.

21. Takata T, Ueda T, Sakasai-Sakai A, Takeuchi M. Generation of glyceraldehyde-derived advanced glycation end-products in pancreatic cancer cells and the potential of tumor promotion. World $\mathrm{J}$ Gastroenterol. 2017;23(27):4910-4919.

22. Takata T, Sakasai-Sakai A, Ueda T, Takeuchi M. Intracellular toxic advanced glycation end-products in cardiomyocytes may cause cardiovascular disease. Sci Rep. 2019;9(1):2121.

23. Takeuchi M, Takino J, Yamagishi S. Involvement of the toxic AGEs (TAGE)-RAGE system in the pathogenesis of diabetic vascular complications: A novel therapeutic strategy. Curr Drug Targets. 2010;11(11):1468-1482.

24. Takeuchi M, Makita Z, Bucala R, Suzuki T, Koike T, Kameda Y. Immunological evidence that noncarboxymethyllysine advanced glycation end-products are produced from short chain sugars and dicarbonyl compounds in vivo. Mol Med. 2000;6(2):114-125.

25. Jinno M, Takeuchi M, Watanabe A, Teruya K, Hirohama J, Eguchi N, et al. Advanced glycation endproducts accumulation compromises embryonic development and achievement of pregnancy by assisted reproductive technology. Hum Reprod. 2011;26(3):604-610.

26. Bais R, James HM, Rofe AM, Conyers RAJ. The purification and properties of human liver ketohexokinase. Biochem J. 1985;230(1):53-60.

27. Vander Jagt DL, Robinson B, Taylor KK, Hunsaker LA. Aldose reductase from human skeletal and heart muscle. J Biol Chem. 1990;265(34):20982-20987.

28. Lee FK, Lee AYW, Lin CXF, Chung SS, Chung SK. Cloning, sequencing, and determination of the sites of expression of mouse sorbitol dehydrogenase cDNA. Eur J Biochem. 1995;230(3):1059-1065.

29. Ahmed MU, Thorpe SR, Baynes JW. Identification of $N^{E}$-carboxymethyllsine as a degradation product of fructoselysine in glycated protein. J. Biol. Chem. 1986;261(11):4889-4894.

30. Taniguchi S, Okinaka M, Tanigawa K, Miwa I. Difference in mechanism between glycelaldehyde-and glucose-induced insulin secretion from isolated rat pancreatic islets. J Biochem. 2000;127(2):289295. 
31. Takahashi H, Tran POT, LeRoy E, Harmon JS, Tanaka Y, Robertson RP. D-glyceraldehyde cause production of intracellular peroxide in pancreatic islets, oxidative stress, and defective beta cell function via non-mitochondrial pathways. J Biol Chem. 2004;279(36):37316-37323.

32. Jojima T, Tomotsune T, lijima T, Akimoto K, Suzuki K, Aso Y. Empagliflozin (an SGLT2 inhibitor), alone or in combination with linagliptin (a DPP-4 inhibitor), prevents steatohepatitis in a novel mouse model of non-alcoholic steatohepatitis and diabetes. Diabetol Metab Syndr. 2016;8:45.

33. Khoshi A, Goodarzi G, Mohammadi R, Arezumand R, Moghbeli M, Najariyan M. Reducing effect of insulin resistance on alpha-synuclein gene expression in skeletal muscle. Diabetol Metab Syndr. 2019;11:99.

34. Glastras SJ, Chen H, Teh R, McGrath RT, Chen J, Pollock CA, et al. Mouse model of diabetes, obesity and related kidney disease. PLoS One. 2016;11(8):e0162131.

\section{Figures}

a

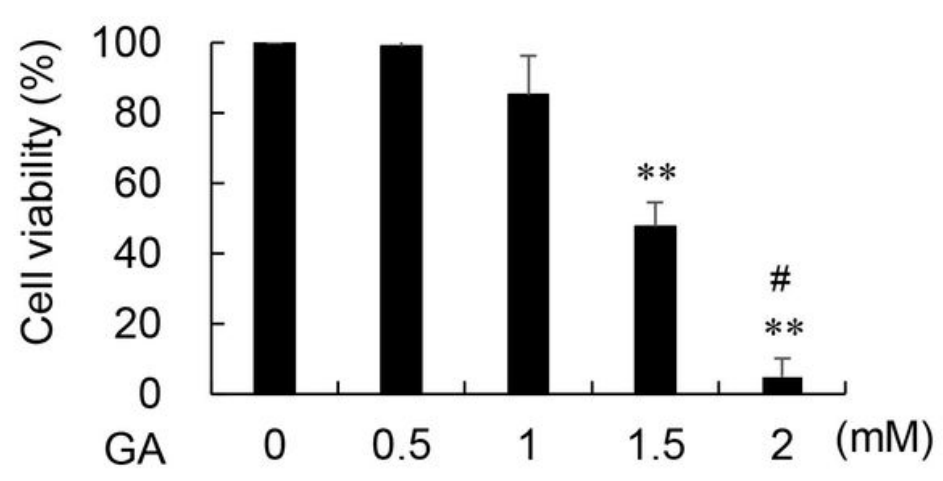

C

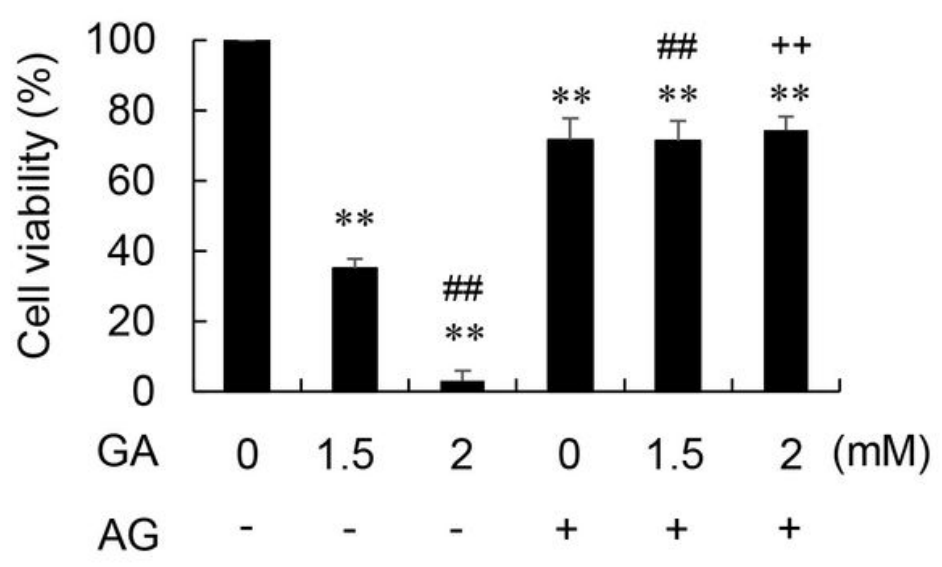

b

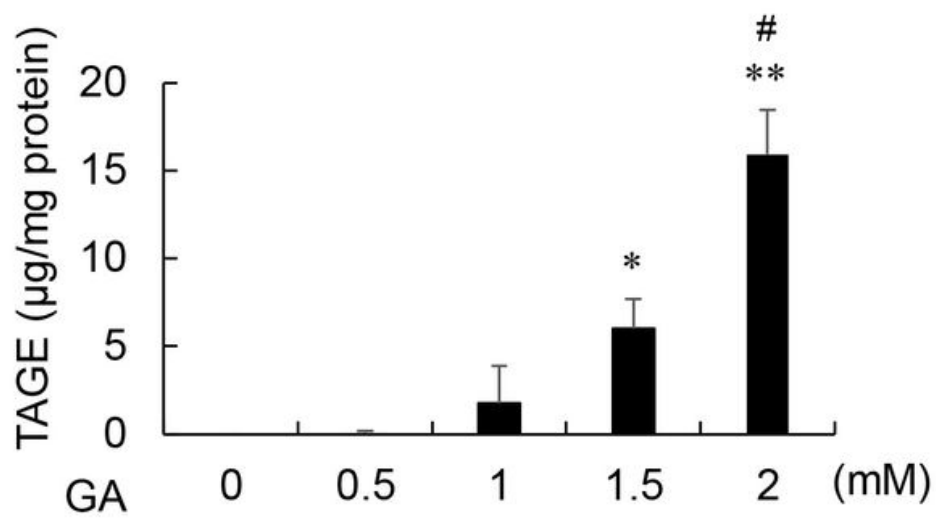

d

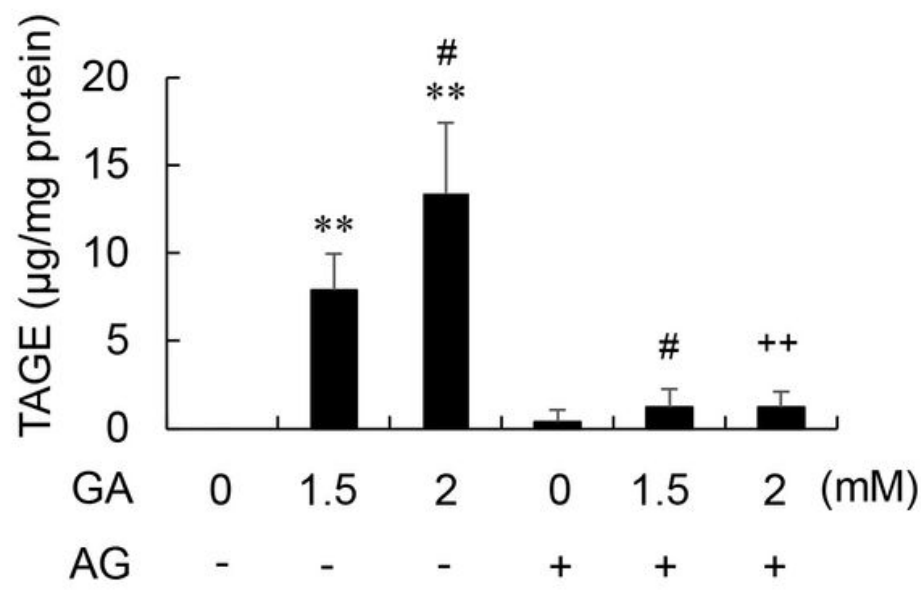




\section{Figure 1}

Cell viability and intracellular TAGE levels in C2C12 cells treated with glyceraldehyde and aminoguanidine. GA: glyceraldehyde. AG: aminoguanidine $(a, b)$ Cells were treated with $0,0.5,1,1.5$, and $2 \mathrm{mM}$ GA for 24 h. (c, d) Cells were pretreated with 0 or $8 \mathrm{mM} \mathrm{AG}$ for $2 \mathrm{~h}$, followed by $0,1.5$, and $2 \mathrm{mM} \mathrm{GA}$ for $24 \mathrm{~h}$. (a, c) Cell viability was assessed by the WST-8 assay, which was performed in three independent experiments. One experiment was performed using 7 wells to calculate the average. Data are shown as means \pm S.D. $(\mathrm{N}=3)$. ( $(\mathrm{b}, \mathrm{d})$ Intracellular TAGE were analyzed using a slot blot analysis. Cell lysates $(2.0 \mu \mathrm{g}$ of protein/lane) were blotted onto a polyvinylidene difluoride membrane. The densities of HRP-linked molecular marker bands were used to correct for differences in densities between membranes. The amount of TAGE was calculated based on a calibration curve for TAGE-BSA. A slot blot analysis was performed in three independent experiments. One experiment was performed using 2 lanes to calculate the average. Data are shown as means \pm S.D. $(N=3)$. $(a, b)$ P-values were based on the Bonferroni test. ${ }^{*}$ p $<0.05$ vs. 0 mM GA. ${ }^{* *} p<0.01$ vs. 0 mM GA. \#p<0.05 vs. $1.5 \mathrm{mM} \mathrm{GA}$. (c, d) P-values were based on Tukey's test. ${ }^{* \star} p<0.01$ vs. 0 mM GA without AG. $\# p<0.05$ vs. $1.5 \mathrm{mM} \mathrm{GA}$ without $A G$. \#\#p<0.01 vs. $1.5 \mathrm{mM}$ GA without $A G .++p<0.01$ vs $2 \mathrm{mM} \mathrm{GA}$ without AG.

a

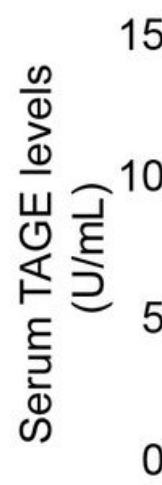

b

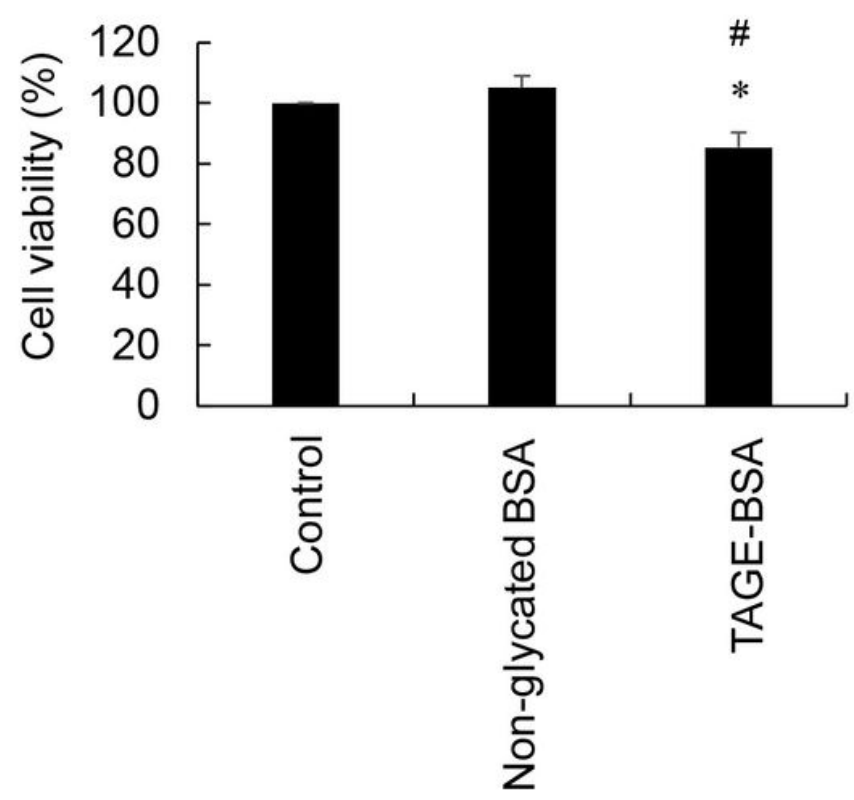

\section{Figure 2}

Serum TAGE levels in STAM mice and cytotoxicity of TAGE-BSA against C2C12 cells. (a) Serum TAGE levels in the four stage groups of STAM mice were measured using an enzyme-linked immunosorbent assay. Results were expresses as TAGE units $(U) / \mathrm{mL}$ of serum, with $1 \mathrm{U}$ corresponding to $1.0 \mu \mathrm{g}$ of TAGEBSA. There were 4 mice in each group. One experiment was performed using 4 wells against the serum of 
one mouse to calculate the average. Data are shown as means \pm S.D. $(\mathrm{N}=4)$. P-values were based on the Bonferroni test. ${ }^{*} \mathrm{p}<0.01$ vs. the no steatosis stage. (b) Cells were treated with 0 and $100 \mu \mathrm{g} / \mathrm{mL}$ nonglycated BSA and TAGE-BSA for $24 \mathrm{~h}$. Cell viability was assessed by the WST-8 assay. This assay was performed in three independent experiments. One experiment was performed using 7 wells to calculate the average. Data are shown as means \pm S.D. $(N=3)$. P-values were based on the Bonferroni test. ${ }^{*} p<0.05$ vs. the control. $\# p<0.05$ vs. the non-glycated BSA treatment.

\section{Supplementary Files}

This is a list of supplementary files associated with this preprint. Click to download.

- SIMaterialsMethodLegends.docx

- FigureS2.jpg

- FigureS3.jpg

- FigureS1.jpg

- Figures4.pptx 